\title{
Extracellular pH is a biomarker enabling detection of breast cancer and liver cancer using CEST MRI
}

\author{
Miaomiao Chen ${ }^{1, *}$, Chaoying Chen ${ }^{2, *}$, Zhiwei Shen $^{1}$, Xiaolei Zhang ${ }^{1}$, Yanzi Chen ${ }^{1}$, \\ Fengfeng Lin ${ }^{1}$, Xilun Ma ${ }^{1}$, Caiyu Zhuang ${ }^{1}$, Yifei Mao ${ }^{1}$, Haochuan Gan ${ }^{1}$, Peidong \\ Chen ${ }^{1}$, Xiaodan Zong ${ }^{1}$ and Renhua $\mathrm{Wu}^{1,3}$ \\ ${ }^{1}$ Department of Medical Imaging, The Second Affiliated Hospital, Medical College of Shantou University, Shantou 515041, \\ China \\ ${ }^{2}$ Department of Clinical Laboratory, The First Affiliated Hospital of Hunan Traditional Chinese Medical College, Zhuzhou \\ 412000, China \\ ${ }^{3}$ Provincial Key Laboratory of Medical Molecular Imaging, Shantou 515041, China \\ *These authors have contributed equally to this work \\ Correspondence to: Renhua Wu, email: rhwu@stu.edu.cn
}

Keywords: liver cancer, pH imaging, breast cancer, ioversol, CEST MRI

Received: January 24, 2017

Accepted: April 03, 2017

Published: April 25, 2017

Copyright: Chen et al. This is an open-access article distributed under the terms of the Creative Commons Attribution License 3.0 ( $C C$ BY 3.0), which permits unrestricted use, distribution, and reproduction in any medium, provided the original author and source are credited.

\section{ABSTRACT}

Extracellular $\mathrm{pH}\left(\mathrm{pH}_{\mathrm{e}}\right)$ decrease is associated with tumor growth, invasion, metastasis, and chemoresistance, which can be detected by chemical exchange saturation transfer (CEST) magnetic resonance imaging (MRI). Here, we demonstrated that ioversol CEST MRI can be exploited to achieve $\mathrm{pH}_{\mathrm{e}}$ mapping of the liver cancer microenvironment. In in vitro studies, we firstly explored whether ioversol signal is $\mathrm{pH}$-dependent, and calculated the function equation between the CEST effects of ioversol and $\mathrm{pH}$ values, in the range of 6.0 to 7.8 , by a ratiometric method. Then we verified the feasibility of this technique and the equation in vivo by applying $\mathbf{p H}_{\mathrm{e}}$ imaging in an MMTV-Erbb2 transgenic mouse breast cancer model, which is often used in CEST $\mathrm{pH}_{\mathrm{e}}$ studies. Furthermore, in vivo ioversol CEST MRI, we were able to map relative $\mathrm{pH}_{\mathrm{e}}$ and differentiate between tumor and normal tissue in a McA-RH7777 rat hepatoma model. This suggests $\mathrm{pH}_{\mathrm{e}}$ may be a useful biomarker for human liver cancer.

\section{INTRODUCTION}

Cancer remains one of the most difficult diseases to cure, with successful treatment primarily relying on early diagnosis. However, the clinical outcome is often insufficient because the patients' quality of life is already poor when they are diagnosed. Thus, clinical success would be greatly enhanced by a noninvasive method for identification of malignant transformation. As reported in recent decades, a reduction in extracellular $\mathrm{pH}\left(\mathrm{pH}_{\mathrm{e}}\right)$ is a characteristic of most malignant tumors [1]. The $\mathrm{pH}_{\mathrm{e}}$ of the tumor microenvironment is typically acidic, in the range of 6.5 to 6.9 , whereas the $\mathrm{pH}_{\mathrm{e}}$ of normal tissue is approximately 7.2 to 7.5 [2]. Extracellular tumor acidosis is the result of increased lactic acid production by high aerobic glycolysis [3] and poor perfusion of tumor cells [4]. This resultant acidity can enhance tumor aggressiveness [5], metastasis [6], chromosomal rearrangements [7], and angiogenesis [8]. Furthermore, low $\mathrm{pH}_{\mathrm{e}}$ also leads to resistance to radiation treatment and specific chemotherapeutics [9]. Acidic tumors are more sensitive to weak-acid chemotherapies such as esomeprazole than to weak-base chemotherapies such as doxorubicin [10-12]. Additionally, modulation of tumor $\mathrm{pH}_{e}$ in a breast cancer mouse model has been shown to reduce metastasis and improve survival [13]. Given the association of acidity with tumor malignancy, accurate measurement of tumor $\mathrm{pH}_{\mathrm{e}}$ may greatly aid in identification of malignancy and tumor invasion, as well as in predicting therapeutic efficacy.

A variety of biomedical imaging methods have been developed to monitor tumor $\mathrm{pH}_{\mathrm{e}}$ in vivo. Optical imaging is a low cost imaging tool with good sensitivity, but can only evaluate surface-accessible tumors [14]. Whole-body PET 
allows rapid measurement of $\mathrm{pH}_{\mathrm{e}}$ [15]. Magnetic resonance spectroscopy provides excellent contrast with limited radiation exposure. However, both methods suffer from limited accuracy, poor sensitivity, low spatial resolution, and limited diagnostic ability $[16,17]$. Based on these limitations, a novel magnetic resonance imaging contrast mechanism called chemical exchange saturation transfer may be desirable. Unlike traditional MRI, which is operated by altering the $T_{1}$ or $T_{2}$ relaxation times of water protons, CEST effects are detected indirectly through the reduced water signal obtained after selectively saturating the exchangeable protons on a CEST agent using radiofrequency (RF) irradiation [18-21]. CEST contrast agents map the $\mathrm{pH}_{\mathrm{e}}$ in the microenvironment in which they distribute [22]. Generally, CEST effects are modulated by several factors including $\mathrm{pH}$, contrast agent concentration, and temperature [23, 24]. In order to minimize the effect of contrast agent concentration, ratiometric methods have been introduced [25]. Several iodinated contrast agents have been employed to measure tissue $\mathrm{pH}_{\mathrm{e}}[26,27]$. Ioversol, a widely used non-ionic X-ray contrast agent with high water solubility and low toxicity, has been shown to be $\mathrm{pH}$-dependent [26]. Ioversol has two amide groups detected $4.3 \mathrm{ppm}$ downfield from water (Figure 1), and has different CEST effects at different RF power levels, allowing an RF power-based ratiometric method to rule out concentration effects [27], and making ioversol more sensitive than traditional iodinated contrast agents such as iopamidol. However, the correlation between the CEST effects of ioversol and $\mathrm{pH}$ value still remains unclear.

There are several reports concerning tumor $\mathrm{CEST}_{\mathrm{pH}}$ imaging, especially in breast cancer, indicating that CEST $\mathrm{pH}_{\mathrm{e}}$ imaging can detect the acidic $\mathrm{pH}_{\mathrm{e}}$ of tumors [4, 12, 27], which is helpful for identifying malignancy in the clinical works. However, for liver cancer, which is of high incidence [28], little is known about its $\mathrm{pH}_{\mathrm{e}}$ imaging. Therefore, we investigated whether CEST MRI could be used as a noninvasive method to diagnose and analyze liver cancer. In this study, we predicted that liver cancer tissue would show a significantly lower CEST signal compared with normal liver tissue. Initially, we aimed to explore the correlation between CEST effects and $\mathrm{pH}$ values of ioversol in vitro, at high magnetic fields, and then applied our findings to a breast cancer model to demonstrate the feasibility of CEST imaging for liver cancer in vivo. Finally, we obtained a $\mathrm{pH}_{\mathrm{e}}$ map of liver cancer, which provides a novel imaging method for liver cancer diagnosis in the clinical setting, and predicting the efficacy of clinical treatment [29].

\section{RESULTS}

\section{CEST effects of ioversol}

As the CEST signals are pH-dependent, we first obtained the CEST Z-spectra of $30 \mathrm{mM}$ ioversol at varying $\mathrm{pH}$ and under a $\mathrm{B}_{1}$ irradiation level of $6 \mu \mathrm{T}$ (Figure 2A). The spectra revealed broad CEST effects, with a peak at $4.3 \mathrm{ppm}$ corresponding to the two exchangeable amide groups. With increasing $\mathrm{pH}$, the signals broadened because of the higher exchange rate. To evaluate the CEST effects, we measured the saturation transfer effect (ST\%) within a $\mathrm{pH}$ range of 6.0 to 7.8 in vitro, using two saturation pulse powers (1.5 and $6 \mu \mathrm{T}$, Figure $2 \mathrm{~B}$ ). As expected, the CEST effects were markedly $\mathrm{pH}$-dependent, with minimum values at $\mathrm{pH}$ 6.0, that gradually increased with $\mathrm{pH}$ up to $\mathrm{pH} 7.5$ at an irradiation power of $6 \mu \mathrm{T}$, and to $\mathrm{pH} 7.2$ at $1.5 \mu \mathrm{T}$, then decreased at higher $\mathrm{pH}$. At high $\mathrm{pH}$, the CEST effect decreases because the exchange rate becomes too high [26]. The unequal CEST effects under different irradiation powers enable a novel ratiometric $\mathrm{pH}$ MRI method first proposed by Longo et al [27].

Theratiometric value is calculated according to the following equation:

$$
R P M=\frac{(1-S T) / S T_{R F 1}}{(1-S T) / S T_{R F 2}}
$$

$\mathrm{ST}_{\mathrm{RF} 1,2}$ represents the saturation transfer (ST) acquired under different RF powers. Then we calculated

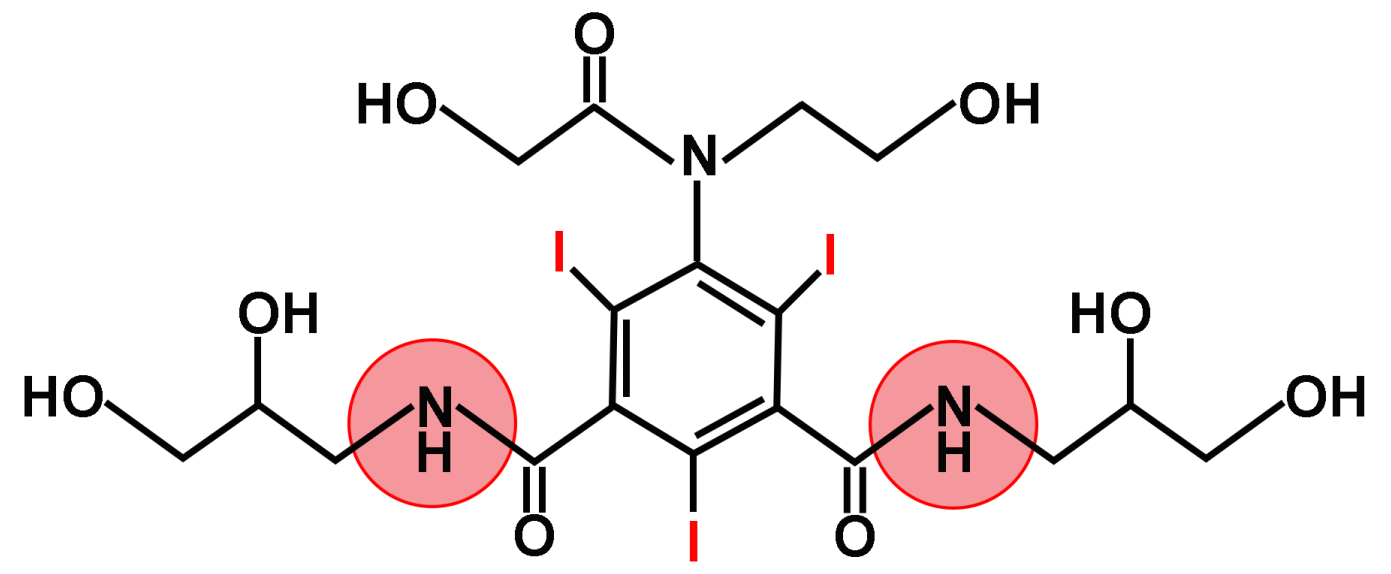

Figure 1: Ioversol chemical structure. Ioversol contains 2 amide groups, 4.3 ppm downfield from the bulk water resonance. 
the RF power mismatch (RPM) by determining the ST\% ratio at RF power levels of 1.5 and $6 \mu \mathrm{T}$ (Figure 2C). The RPM curve demonstrated that the ratiometric values increased exponentially with the $\mathrm{pH}$ value in the $\mathrm{pH}$ range of 6.0 to 7.8 , with the $\log _{10}$ ratio of the CEST effects exhibiting an excellent correlation with $\mathrm{pH}\left(\mathrm{R}^{2}=0.98, p\right.$ $<0.001$, Figure 2D).

\section{In vitro imaging of ioversol}

Next, to determine whether the corresponding $\mathrm{pH}$ images could distinguish the ioversol solutions at different $\mathrm{pH}$ values, we performed experiments on 7 tubes of 30 $\mathrm{mM}$ ioversol at $\mathrm{pH} 6.0$ to 7.8 and under $\mathrm{B}_{1}$ irradiation levels of 1.5 and $6 \mu \mathrm{T}$. Figure $3 \mathrm{~A}$ and Figure $3 \mathrm{~B}$ show strong CEST signal changes occurred with increasing $\mathrm{pH}$, with the signal changes at $6 \mu \mathrm{T}$ (Figure 3B) being greater than that at $1.5 \mu \mathrm{T}$ (Figure 3A). Then we obtained a $\mathrm{pH}$ map by calculating from the ratiometric map, which was calculated from the ratio of the corresponding ST images (Figure 3C). The $\mathrm{pH}$ map showed that the different $\mathrm{pH}$ values could be clearly distinguished by the colorful signals. The calculated $\mathrm{pH}$ values strongly correlate with the titrated $\mathrm{pH}$ values, with $\mathrm{pH}_{(\mathrm{MRI})}=\mathrm{pH}_{\text {(titrated) }}+2 \mathrm{E}^{-0.5}\left(\mathrm{R}^{2}\right.$

A

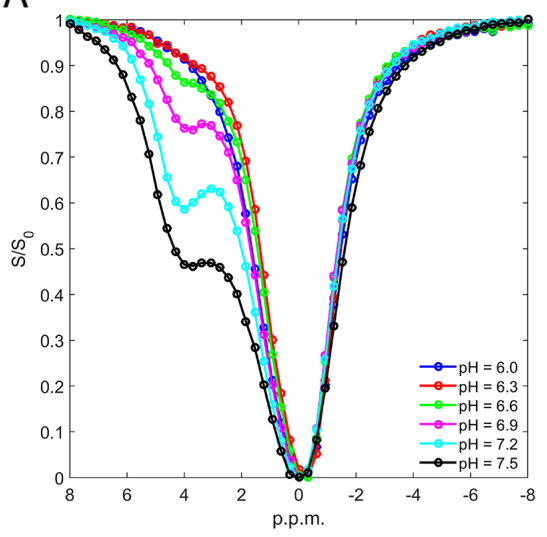

C

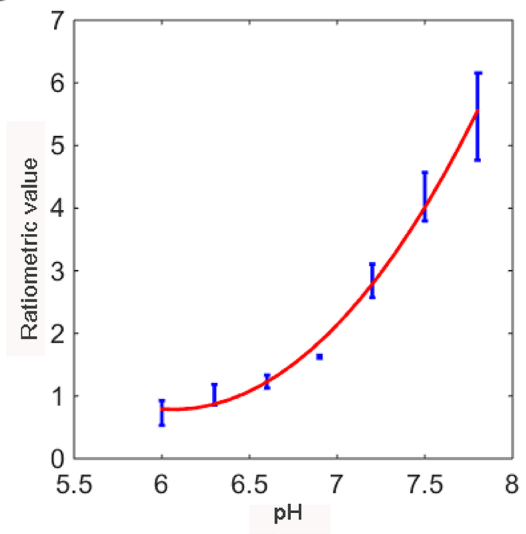

$=0.98, p<0.001$ ) (Figure 3E). It should be noted that, this CEST agent has been previously used for in vivo applications, so we must ensure that it is concentrationindependent. To answer this question, we prepared 6 tubes of pH 7.2 ioversol solution with different ioversol concentrations (10-60 mM). The $\mathrm{pH}$ map revealed no significant difference between these ioversol solutions (Figure 3D), and the calculated $\mathrm{pH}$ values were obtained within a small error for all concentrations (Figure $3 \mathrm{~F})$, confirming that $\mathrm{pH}$ quantification by ioversol CEST imaging can indeed measure $\mathrm{pH}$ over the 6 -fold concentration range used in this study.

\section{In vivo imaging of breast cancer}

To assess whether our in vitro results are relevant for in vivo studies, we first applied ioversol CEST $\mathrm{pH}_{\mathrm{e}}$ in themouse mammary tumor virus (MMTV)-Erbb2 transgenic mouse breast tumor model, which is often used in CEST $\mathrm{pH}_{\mathrm{e}}$ studies. The axial $\mathrm{T}_{2}$ image of a breast cancer before injection shows the location of the tumor (Figure 4A). Then we directly injected ioversol into the tail vein, whereupon a strong CEST signal was generated in the tumor. The CEST ST maps, from the tumor region at 1.5

B

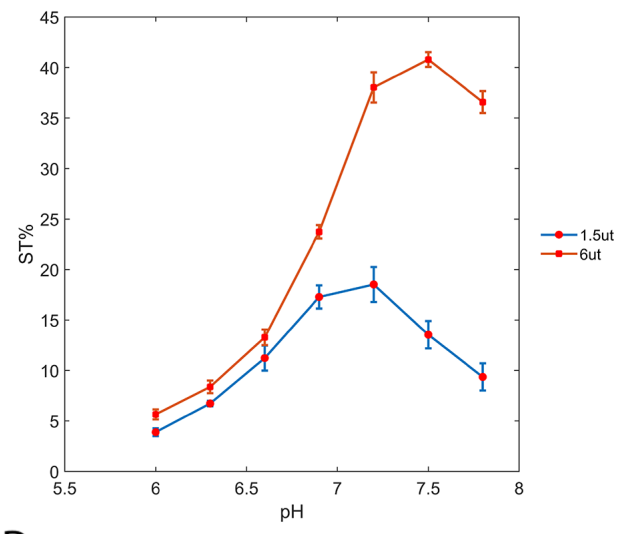

D

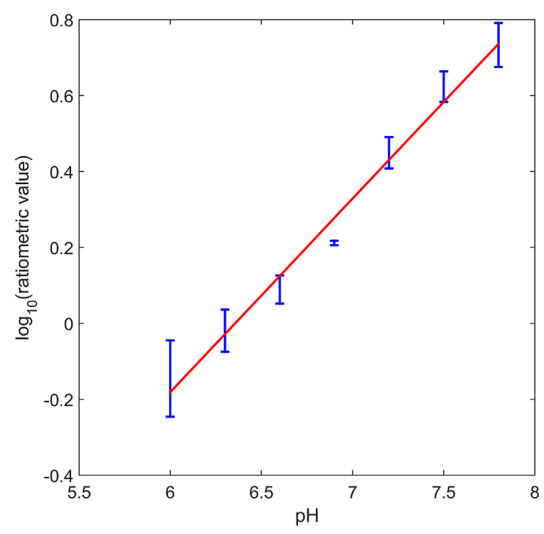

Figure 2: Ioversol exhibits a strong CEST signal. (A) Z-spectra of $30 \mathrm{mM}$ ioversol at different $\mathrm{pH}$ values at $6 \mu \mathrm{T}$. (B) Ioversol ST\% depends on $\mathrm{pH}$ at RF saturation powers of 1.5 and $6 \mu \mathrm{T}$. (C) The CEST ratio was exponentially correlated with $\mathrm{pH}$. (D) The log ${ }_{10}$ ratio of the CEST effect linearly correlated with $\mathrm{pH}$. 
$\mu \mathrm{T}$ (Figure 4B) and $6 \mu \mathrm{T}$ (Figure 4C) power saturation, showed that at $6 \mu \mathrm{T}$ in the tumor (Figure 4C) was brighter than at $1.5 \mu \mathrm{T}$ (Figure 4B), owing to the faster exchange rate. The tumor $\mathrm{pH}_{\mathrm{e}}$ map (ratiometric map in Figure 4B and $4 \mathrm{C}$ ) of the tumor superimposed on the anatomic MR image shows an acidic extracellular environment, in the tumor region, corresponding to $\mathrm{pH}_{\mathrm{e}}$ values between 6.36.9 (Figure 4D).

\section{In vivo imaging of normal liver and liver tumors}

Next, we tested whether ioversol CEST imaging could be performed on liver tissue. A reasonable CEST signal was observed throughout the normal liver at RF powers of 1.5 and $6 \mu \mathrm{T}$ (Figure $5 \mathrm{~B}$ and $5 \mathrm{C}$, respectively), and the signal of the calculated $\mathrm{pH}_{\mathrm{e}}$ map (Figure 5D) displayed well in the region of the liver on the $\mathrm{T}_{2}$ image (Figure 5A), indicating ioversol CEST $\mathrm{pH}_{\mathrm{e}} \mathrm{MRI}$ is feasible for liver applications. In an effort to determine whether ioversol CEST imaging could differentiate between liver tumor and normal tissue, we transplanted McA-RH7777 rat hepatoma cells into the left lateral hepatic lobe of Sprague-Dawley (SD) rats and allowed tumors to form for 14 days prior to ioversol CEST MRI. The axial $\mathrm{T}_{2}$ image
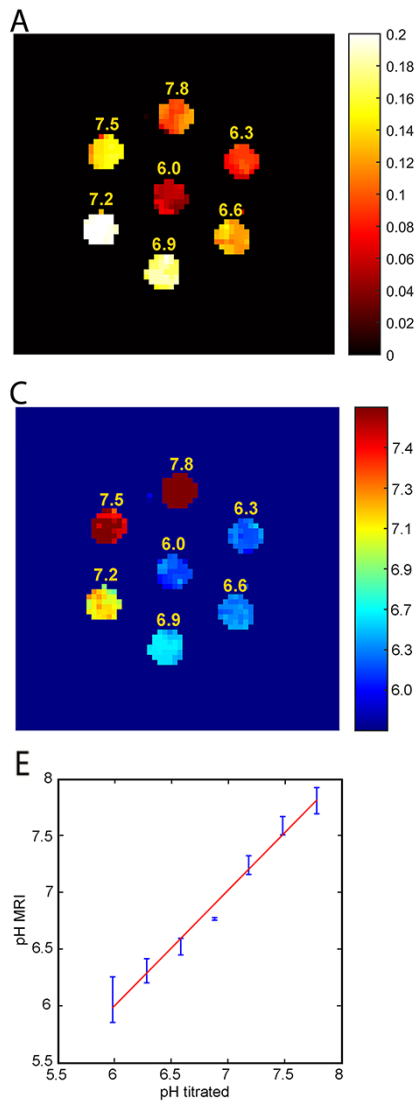

showed that the tumor diameter was $9 \mathrm{~mm}$ (Figure 6A). After injecting ioversol, the liver tumor exhibited a lower CEST signal compared with the normal liver tissue, at both $1.5 \mu \mathrm{T}$ (Figure 6B) and $6 \mu \mathrm{T}$ (Figure 6C) irradiation. The ioversol CEST $\mathrm{pH}_{\mathrm{e}}$ maps were obtained from the rat tumors at $7 \mathrm{~T}$ (Figure 6D). The $\mathrm{pH}_{\mathrm{e}}$ map clearly distinguished tumor from normal tissue, and the $\mathrm{pH}_{\mathrm{e}}$ of the tumor was lower than that of normal liver tissue in all 10 rats examined ( $p<0.05$, Figure 5E). Interestingly, we also found in the ioversol CEST $\mathrm{pH}_{\mathrm{e}}$ image that the tumor region was slightly greater than the region obtained by $\mathrm{T}_{2}$ imaging in both a breast and liver tumor model. Images of the tissue stained with hematoxylin and eosin (HE) are shown in the Supplementary Figure 1.

\section{DISCUSSION}

Our findings provide the first evidence that ioversol CEST $\mathrm{pH}_{\mathrm{e}}$ MRI can accurately measure liver and breast tumor $\mathrm{pH}_{\mathrm{e}}$ in a concentration-independent manner, with excellent spatial resolution. In phantom studies, we showed that the $\log _{10}$ ratio of the CEST effect was linearly proportional to the $\mathrm{pH}$ value in the range of 6.0-7.8. These results extend the study of Longo et al., who only showed
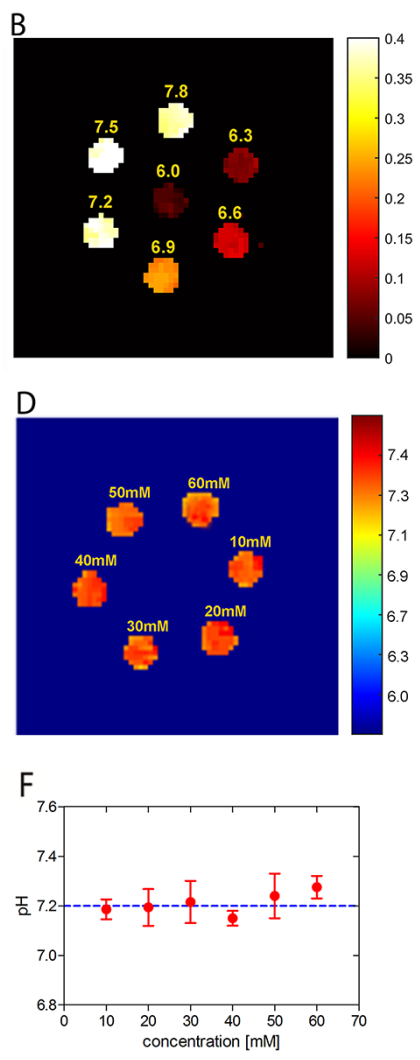

Figure 3: Ioversol CEST MR images of a phantom consisting of test tubes. ST images of $30 \mathrm{mM}$ ioversol at different $\mathrm{pH}$ values under RF powers of $1.5 \mu \mathrm{T}$ (A) and $6 \mu \mathrm{T}$ (B). (C) $\mathrm{pH}$ map calculated using the corresponding ST images (A and B). (D) $\mathrm{pH}$ mapping is independent of ioversol concentration. (E) The calculated $\mathrm{pH}$ values strongly correlate with the titrated $\mathrm{pH}$ values. (F) $\mathrm{Mean} \mathrm{pH}$ values calculated for several concentrations. 
A

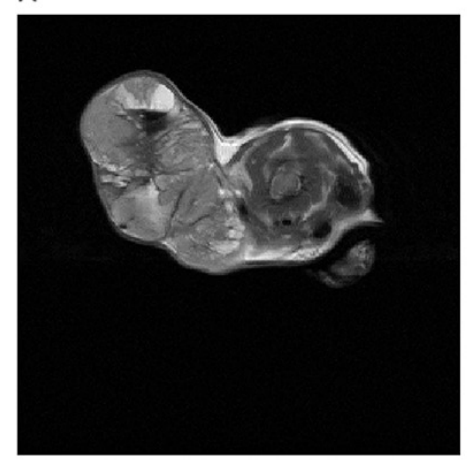

C

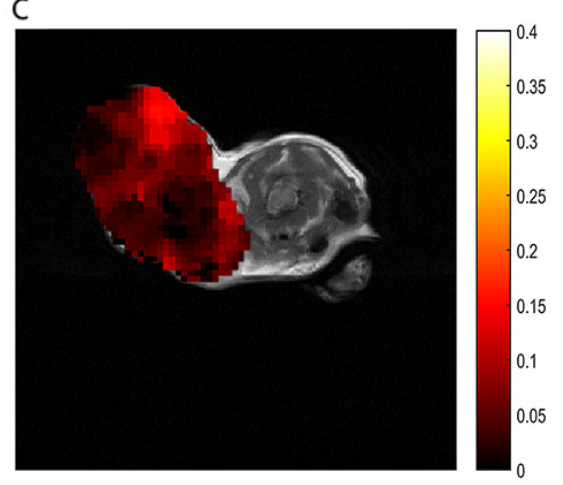

B

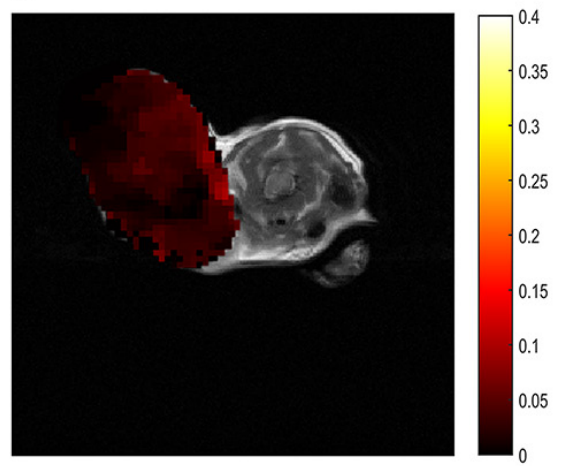

D

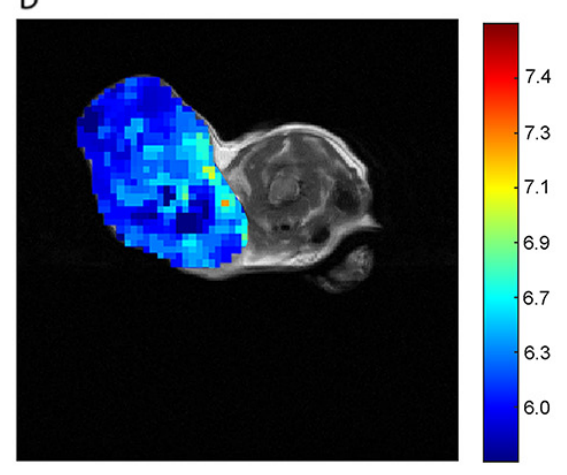

Figure 4: In vivo CEST imaging of breast cancer. (A) $\mathrm{T}_{2}$ breast cancer image. ST map after ioversol injection at $1.5 \mu \mathrm{T}$ (B) and 6 $\mu \mathrm{T}$ (C). (D) The $\mathrm{pH}_{\mathrm{e}}$ map calculated by using corresponding ST images (B and C).

A

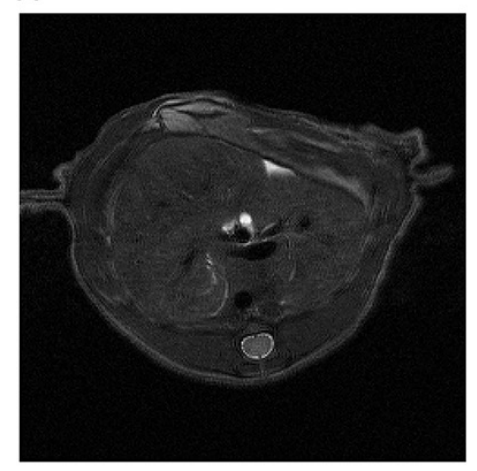

C

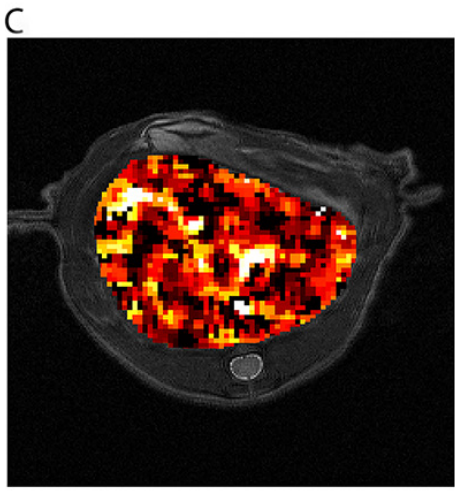

B

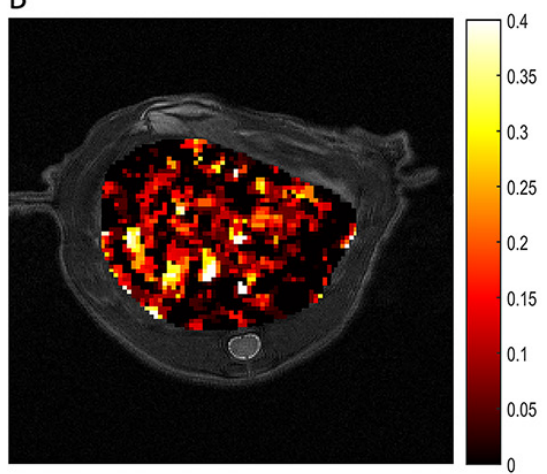

D
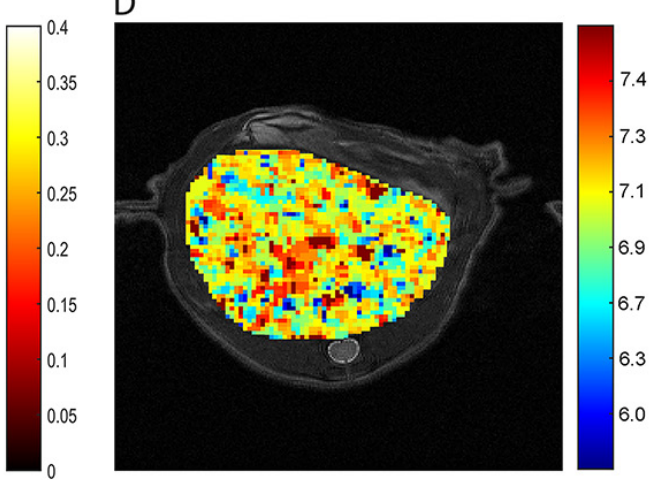

Figure 5: CEST imaging of normal liver tissue. (A) $\mathrm{T}_{2}$ liver image. ST map after ioversol injection at $1.5 \mu \mathrm{T}$ (B) and $6 \mu \mathrm{T}$ (C). (D) The $\mathrm{pH}_{\mathrm{e}}$ map calculated using the corresponding ST images (B and C). 
that ioversol is pH-dependent [26]. Moreover, compared with traditional CEST agents that have two CEST effects in one Z-spectrum, ioversol has two Z-spectra that may be more sensitive because the two CEST effects from different RF levels do not interact with each other. However, besides the contrast agent concentration, the CEST effect also depends on temperature, so attention must be paid to $\mathrm{pH}$ measurements at the same temperature during experiments [30].

Compared with the mouse xenograft models in previous reports, we choose the MMTV-Erbb2 transgenic mouse breast tumor model for our study because this reflects human breast cancer characteristics more accurately [31]. As we can see from the results, the $\mathrm{pH}_{\mathrm{e}}$ of the tumor region was fairly acidic, in the range of 6.3-6.9, suggesting a high degree of malignancy. We further show that liver cancer tissue had lower CEST signals compared with normal tissue. For our liver tumor model, we chose an orthotopic transplantation tumor model, using McA-RH7777 rat hepatoma cells, instead of a subcutaneous tumor model, because it simulates the characteristics and environment of human liver cancer. However, the accompanying challenges could not be neglected, especially motion artefacts and field inhomogeneity corrections. To minimize motion artifacts from breathing, we used a respiratory gating device and bellyband to reduce the respiratory amplitude. We also adopted motion correction and $\mathrm{B}_{0}$-shift correction to improve the image quality. In addition, a duration of 15 minutes post injection was allowed, to permit stabilization and prolonged accumulation of the contrast agent within the tumor, during the CEST MRI acquisition. However, the signal-to-noise ratio (SNR) in the liver of liver and liver cancer images was not always satisfactory, compared with kidney $\mathrm{pH}$ maps previously reported $[25,32]$. This is mainly because: 1) the extracellular concentration of agent that accumulates in the liver is lower than that in the kidney [33, 34], and 2) the effect of breathing motion more profoundly affects the liver compared with that to kidney. The $\mathrm{pH}_{\mathrm{e}}$ map of the tumor region was slightly larger than that of the $\mathrm{T}_{2}$ map, indicating that either the acid diffused out of the tumor, or the $\mathrm{pH}_{\mathrm{e}}$ map was affected by noise, remaining to be further elucidated.

Future studies will be needed to optimize the parameters of this approach, for purpose of improving the image SNR. Shortening the acquisition time while maintaining good SNR by reducing the offset number also needs further investigation [35]. Moreover, as more and more patients accept chemotherapy, we should further explore and use CEST pH MRI to assess the response of liver cancer following chemotherapy in mouse models, and now we have compounded a nano-targeted chemotherapy medicine. Additionally, we will also attempt to translate this technique from high field to lower field strengths. It is important to note that we are preparing to explore ioversol $\mathrm{pH}$ imaging using a 3T MR scanner, as $\mathrm{pH}_{\mathrm{e}}$ imaging with iodinated agents and CEST liver imaging in patients has been recently reported $[35,36]$. Future studies using this

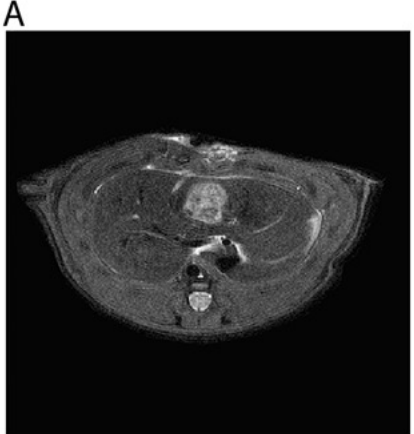

c

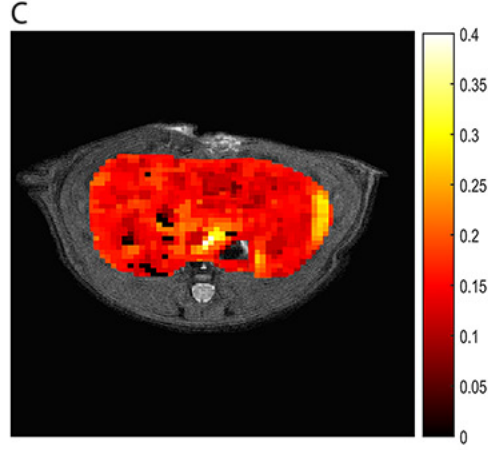

B

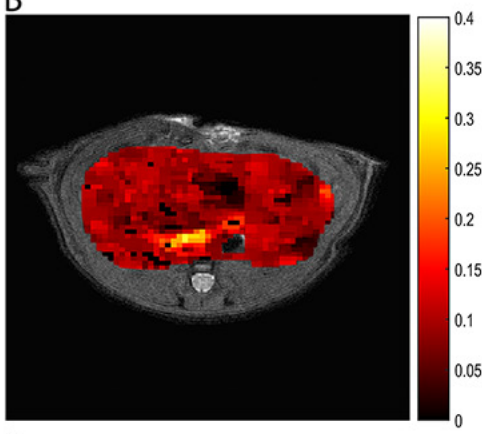

$\mathrm{D}$

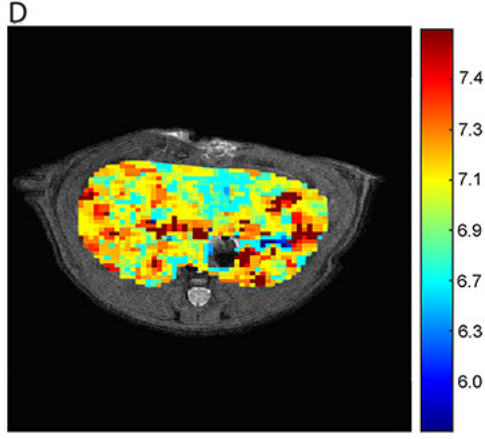

$\mathrm{E}$

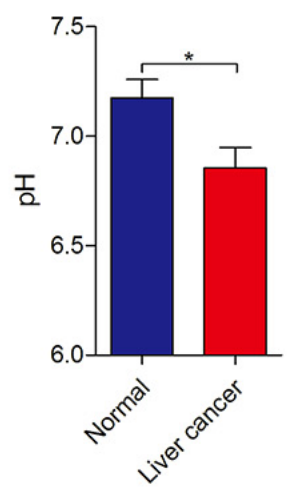

Figure 6: CEST imaging of liver cancer. (A) $\mathrm{T}_{2}$ liver cancer image. ST map after ioversol injection at $1.5 \mu \mathrm{T}$ (B) and $6 \mu \mathrm{T}$ (C). (D) The $\mathrm{pH}_{\mathrm{e}}$ map calculated using corresponding ST images (B and C). (E) $\mathrm{pH}$ values of the two tissues showing a significant difference $(* p<$ 0.05 , Student's $t$-test). Error bars represent the standard deviation $(\mathrm{n}=10)$ 
approach may provide new insights into liver cancer development and biomarkers for the clinical studies.

\section{MATERIALS AND METHODS}

\section{Phantom preparation}

One phantom contained seven micro-centrifuge tubes with $30 \mathrm{mM}$ ioversol (Hengrui Medicine Co., Ltd., Jiangsu, China) in phosphate-buffered solution, titrated using $\mathrm{HCl}$ or $\mathrm{NaOH}$, to various $\mathrm{pH}$ values ranging from 6.0 to 7.8 in units of 0.3 . The other phantom contained six micro-centrifuge tubes of $\mathrm{pH} 7.2$ ioversol, at concentrations from 10 to $60 \mathrm{mM}$, in phosphate-buffered solution. The phantoms were filled with agarose solution and solidified at $37^{\circ} \mathrm{C}$.

\section{Cell culture}

The McA-RH7777 rat hepatoma cell line was purchased from the Chinese Academy of Sciences (Shanghai, China). Cells were cultured in Dulbecco's modified Eagle's medium (DMEM), supplemented with $10 \%$ fetal bovine serum and $2 \%$ penicillin and streptomycin, at $37^{\circ} \mathrm{C}$ in a humidified atmosphere containing $5 \% \mathrm{CO}_{2}$. The cell media was changed every 2 days.

\section{Liver cancer model}

All animal experiments were performed according to protocols approved by the Animal Care and Use Committee of the Medical College of Shantou University. Ten female SD rats (Shantou University Medical Center Laboratory, Shantou, China), weighing 250 to $300 \mathrm{~g}$, were used for this study. SD rats were anesthetized by injecting a solution of chloral hydrate into the enterocoelia. Then, a midline mini-laparotomy was performed and the left lateral hepatic lobe was exposed. McA-RH7777 rat hepatoma cells $\left(1 \times 10^{7}\right)$ were prepared in $0.05 \mathrm{~mL}$ of a mixture of serum-free DMEM and Matrigel, and injected into the left lateral lobe [37]. At the end of the operation, the abdominal incisions were closed using a two-layer technique, and tumors were allowed to form for 14 days.

\section{Breast cancer model}

Six MMTV-Erbb2 transgenic mice were purchased from Jackson Laboratories and bred in-house. This model carries an activated Erbb2 oncogene driven by the MMTV promoter, leading to the overexpression of constitutively active oncogenic Erbb2 in the breast [38]. These mice develop spontaneous mammary tumors after a latency period and are a good model for human breast cancer.

\section{MRI}

Experiments were performed on a 7T animal MRI scanner (Agilent, VNMRS, USA) at room temperature using a $63 \mathrm{~mm}$ internal diameter standard ${ }^{1} \mathrm{H}$ volume coil (single-channel). For $\mathrm{T}_{2}$ MRI, we used a fast spin echo sequence. The parameters were as follows: relaxation time $(\mathrm{TR})=2000 \mathrm{~ms}$; echo time $(\mathrm{TE})=4.1 \mathrm{~ms}$; number of excitations $($ NEX $)=1$; field of view $($ FOV $)=50 \times 50$ $\mathrm{mm}$; slice thickness $=3 \mathrm{~mm}$; matrix $=128 \times 128$. CEST images were acquired using an echo planner imaging sequence. Continuous wave RF saturation was applied for $5 \mathrm{~s}$, with RF irradiation powers of $1.5,3,6$, and $9 \mu \mathrm{T}$ for investigating the CEST Z-spectra of phantoms, and 1.5 and $6 \mu \mathrm{T}$ for CEST imaging. The other parameters were as follows: $\mathrm{TR}=6.0 \mathrm{~s}$; $\mathrm{TE}=4.1 \mathrm{~ms} ; \mathrm{NEX}=4 ; \mathrm{FOV}$ $=30 \times 30 \mathrm{~mm}$ for in vitro and $50 \times 50 \mathrm{~mm}$ for in vivo experiments; slice thickness $=3 \mathrm{~mm}$; matrix $=64 \times 64$. We obtained Z-spectra ranging from -8 to $8 \mathrm{ppm}$, at intervals of $0.31 \mathrm{ppm} \mathrm{B}_{0}$, and $\mathrm{B}_{1}$ field inhomogeneities were mapped and used for removing field inhomogeneityinduced artifacts during the Z-spectra reconstruction [18].

\section{Animal preparation}

During MR imaging, mice were anesthetized by inhaling a mixture of isoflurane (1.5\%) and oxygen. Breathing rate was monitored throughout the in vivo MRI experiment using a respiratory gating device. Respiratory gating was performed by triggering the start of the pulse sequence soon after the end of the exhalation, with a rate of 40 breaths per min. Ioversol (dose, $4 \mathrm{~g} \mathrm{I} / \mathrm{kg}$ body weight) solution was slowly injected into the tail vein, and we acquired CEST images at two RF power 1.5 and $6.0 \mu \mathrm{T}) 15 \mathrm{~min}$ after ioversol injection.

After MRI acquisition, mice were sacrificed and the tumor tissue were excised. Tissue was sectioned and stained with HE for microscopy.

\section{Statistical analysis}

All CEST images were analyzed using MATLAB (The Mathworks, Inc., Natick, MA, USA) [39, 40]. Z-spectra were interpolated by smoothing splines. $\mathrm{B}_{0}$-shift correction was defined as the lowest intensity point in the $\mathrm{Z}$-spectrum of each voxel as the central water frequency, then the other data points in the voxel's Z-spectrum were shifted accordingly [34]. Saturation transfer efficiency $(\mathrm{ST} \%)$ was measured by $\mathrm{MTR}_{\text {asym }}=\left(\mathrm{S}_{\Delta \omega}-\mathrm{S}_{+\Delta \omega}\right) / \mathrm{S}_{0}$, and $\mathrm{S}_{-\Delta \omega}, \mathrm{S}_{+\Delta \omega}$, with $\mathrm{S}_{0}$ representing the water signal with a saturation frequency offset at $-\Delta \omega,+\Delta \omega$ with and without saturation, respectively. Assessment of the $\mathrm{pH}_{\mathrm{e}}$ difference between the tumor and normal liver tissue were analyzed using Student's $t$-tests, and a $p<0.05$ was considered significant. 


\section{Author contributions}

M.C. and R.W. designed the project; M.C. and C.C. drafted the manuscript; C.M. and Z.S. performed the MRI experiments; M.C. and C.C. performed animal studies; M.C., C.C. and X.Z. analyzed the data; R.W. critically reviewed and revised the manuscript.

\section{ACKNOWLEDGMENTS}

We thank Stanley Lin (Shantou University Medical College) for proofreading the manuscript.

\section{FUNDING}

This project was supported by the National Natural Science Foundation of China (Grant No. 81471730) and the National High Technology Research and Development Program (863 Program) of China (Program No. 2014AA021101).

\section{REFERENCES}

1. Webb BA, Chimenti M, Jacobson MP, Barber DL. Dysregulated $\mathrm{pH}$ : a perfect storm for cancer progression. Nat Rev Cancer. 2011; 11: 671-7. doi: 10.1038/nrc3110.

2. Gatenby RA, Gawlinski ET, Gmitro AF, Kaylor B, Gillies RJ. Acid-mediated tumor invasion: a multidisciplinary study. Cancer Res. 2006; 66: 5216-23. doi: 10.1158/00085472.CAN-05-4193.

3. Gatenby RA, Gillies RJ. Why do cancers have high aerobic glycolysis? Nat Rev Cancer. 2004; 4: 891-9. doi: 10.1038/ nrc1478.

4. Hashim AI, Zhang X, Wojtkowiak JW, Martinez GV, Gillies RJ. Imaging $\mathrm{pH}$ and metastasis. NMR Biomed. 2011; 24: 582-91. doi: 10.1002/nbm.1644.

5. Estrella V, Chen T, Lloyd M, Wojtkowiak J, Cornnell $\mathrm{HH}$, Ibrahim-Hashim A, Bailey K, Balagurunathan Y, Rothberg JM, Sloane BF, Johnson J, Gatenby RA, Gillies RJ. Acidity generated by the tumor microenvironment drives local invasion. Cancer Res. 2013; 73: 1524-35. doi: 10.1158/0008-5472.CAN-12-2796.

6. Gillies RJ, Gatenby RA. Hypoxia and adaptive landscapes in the evolution of carcinogenesis. Cancer Metastasis Rev. 2007; 26: 311-7. doi: 10.1007/s10555-007-9065-z.

7. Morita T, Nagaki T, Fukuda I, Okumura K. Clastogenicity of low $\mathrm{pH}$ to various cultured mammalian cells. Mutat Res. 1992; 268: 297-305.

8. Shi Q, Le X, Wang B, Abbruzzese JL, Xiong Q, He Y, Xie K. Regulation of vascular endothelial growth factor expression by acidosis in human cancer cells. Oncogene. 2001; 20: 3751-6. doi: 10.1038/sj.onc. 1204500.

9. Bix G, Castello R, Burrows M, Zoeller JJ, Weech M, Iozzo RA, Cardi C, Thakur ML, Barker CA, Camphausen K, Iozzo
RV. Endorepellin in vivo: targeting the tumor vasculature and retarding cancer growth and metabolism. J Natl Cancer Inst. 2006; 98: 1634-46. doi: 10.1093/jnci/djj441.

10. Robey IF, Baggett BK, Kirkpatrick ND, Roe DJ, Dosescu J, Sloane BF, Hashim AI, Morse DL, Raghunand N, Gatenby RA, Gillies RJ. Bicarbonate increases tumor $\mathrm{pH}$ and inhibits spontaneous metastases. Cancer Res. 2009; 69: 2260-8. doi: 10.1158/0008-5472.CAN-07-5575.

11. Mahoney BP, Raghunand N, Baggett B, Gillies RJ. Tumor acidity, ion trapping and chemotherapeutics. I. Acid $\mathrm{pH}$ affects the distribution of chemotherapeutic agents in vitro. Biochem Pharmacol. 2003; 66: 1207-18.

12. Chen LQ, Howison CM, Jeffery JJ, Robey IF, Kuo PH, Pagel MD. Evaluations of extracellular $\mathrm{pH}$ within in vivo tumors using acidoCEST MRI. Magn Reson Med. 2014; 72 : 1408-17. doi: 10.1002/mrm.25053.

13. Raghunand N, Mahoney BP, Gillies RJ. Tumor acidity, ion trapping and chemotherapeutics. II. pH-dependent partition coefficients predict importance of ion trapping on pharmacokinetics of weakly basic chemotherapeutic agents. Biochem Pharmacol. 2003; 66: 1219-29.

14. Hassan M, Riley J, Chernomordik V, Smith P, Pursley R, Lee SB, Capala J, Gandjbakhche AH. Fluorescence lifetime imaging system for in vivo studies. Mol Imaging. 2007; 6: 229-36.

15. Vavere AL, Biddlecombe GB, Spees WM, Garbow JR, Wijesinghe D, Andreev OA, Engelman DM, Reshetnyak YK, Lewis JS. A novel technology for the imaging of acidic prostate tumors by positron emission tomography. Cancer Res. 2009; 69: 4510-6. doi: 10.1158/0008-5472. CAN-08-3781.

16. Khramtsov VV, Grigor'ev IA, Foster MA, Lurie DJ, Nicholson I. Biological applications of spin $\mathrm{pH}$ probes. Cell Mol Biol (Noisy-le-grand). 2000; 46: 1361-74.

17. Gillies RJ, Morse DL. In vivo magnetic resonance spectroscopy in cancer. Annu Rev Biomed Eng. 2005; 7: 287-326. doi: 10.1146/annurev.bioeng.7.060804.100411.

18. Cai K, Haris M, Singh A, Kogan F, Greenberg JH, Hariharan H, Detre JA, Reddy R. Magnetic resonance imaging of glutamate. Nat Med. 2012; 18: 302-6. doi: 10.1038/nm.2615.

19. Sherry AD, Woods M. Chemical exchange saturation transfer contrast agents for magnetic resonance imaging. Annu Rev Biomed Eng. 2008; 10: 391-411. doi: 10.1146/ annurev.bioeng.9.060906.151929.

20. Song X, Airan RD, Arifin DR, Bar-Shir A, Kadayakkara DK, Liu G, Gilad AA, van Zijl PC, McMahon MT, Bulte JW. Label-free in vivo molecular imaging of underglycosylated mucin-1 expression in tumour cells. Nat Commun. 2015; 6: 6719. doi: 10.1038/ncomms7719.

21. Sun PZ, Lu J, Wu Y, Xiao G, Wu R. Evaluation of the dependence of CEST-EPI measurement on repetition time, RF irradiation duty cycle and imaging flip angle for 
enhanced pH sensitivity. Phys Med Biol. 2013; 58: N22940. doi: 10.1088/0031-9155/58/17/N229.

22. Ward KM, Balaban RS. Determination of $\mathrm{pH}$ using water protons and chemical exchange dependent saturation transfer (CEST). Magn Reson Med. 2000; 44: 799-802.

23. Wu R, Longo DL, Aime S, Sun PZ. Quantitative description of radiofrequency (RF) power-based ratiometric chemical exchange saturation transfer (CEST) $\mathrm{pH}$ imaging. NMR Biomed. 2015; 28: 555-65. doi: 10.1002/nbm.3284.

24. Wu R, Liu CM, Liu PK, Sun PZ. Improved measurement of labile proton concentration-weighted chemical exchange rate $(\mathrm{k}(\mathrm{ws}))$ with experimental factor-compensated and $\mathrm{T}$ (1)-normalized quantitative chemical exchange saturation transfer (CEST) MRI. Contrast Media Mol Imaging. 2012; 7: 384-9. doi: 10.1002/cmmi.505.

25. Longo DL, Dastru W, Digilio G, Keupp J, Langereis S, Lanzardo S, Prestigio S, Steinbach O, Terreno E, Uggeri F, Aime S. Iopamidol as a responsive MRI-chemical exchange saturation transfer contrast agent for $\mathrm{pH}$ mapping of kidneys: in vivo studies in mice at 7 T. Magn Reson Med. 2011; 65: 202-11. doi: 10.1002/mrm.22608.

26. Longo DL, Michelotti F, Consolino L, Bardini P, Digilio G, Xiao G, Sun PZ, Aime S. In vitro and in vivo assessment of nonionic iodinated radiographic molecules as chemical exchange saturation transfer magnetic resonance imaging tumor perfusion agents. Invest Radiol. 2016; 51: 155-62. doi: 10.1097/RLI.0000000000000217.

27. Longo DL, Sun PZ, Consolino L, Michelotti FC, Uggeri F, Aime S. A general MRI-CEST ratiometric approach for $\mathrm{pH}$ imaging: demonstration of in vivo $\mathrm{pH}$ mapping with iobitridol. J Am Chem Soc. 2014; 136: 14333-6. doi: 10.1021/ja5059313.

28. El-Serag HB. Hepatocellular carcinoma. N Engl J Med. 2011; 365: 1118-27. doi: 10.1056/NEJMra1001683.

29. Raghunand N, Gillies RJ. pH and chemotherapy. Novartis Found Symp. 2001; 240: 199-211; discussion 65-8.

30. Moon BF, Jones KM, Chen LQ, Liu P, Randtke EA, Howison CM, Pagel MD. A comparison of iopromide and iopamidol, two acidoCEST MRI contrast media that measure tumor extracellular $\mathrm{pH}$. Contrast Media Mol Imaging. 2015; 10: 446-55. doi: 10.1002/cmmi.1647.

31. Koren S, Bentires-Alj M. Breast tumor heterogeneity: source of fitness, hurdle for therapy. Mol Cell. 2015; 60: 537-46. doi: 10.1016/j.molcel.2015.10.031.
32. Longo DL, Busato A, Lanzardo S, Antico F, Aime S. Imaging the $\mathrm{pH}$ evolution of an acute kidney injury model by means of iopamidol, a MRI-CEST pH-responsive contrast agent. Magn Reson Med. 2013; 70: 859-64. doi: $10.1002 / \mathrm{mrm} .24513$.

33. Meurer K, Kelsch B, Hogstrom B. The pharmacokinetic profile, tolerability and safety of the iodinated, non-ionic, dimeric contrast medium Iosimenol 340 injection in healthy human subjects. Acta Radiol. 2015; 56: 581-6. doi: 10.1177/0284185114534414.

34. Gharekhanloo F, Torabian S. Comparison of allergic adverse effects and contrast enhancement between iodixanol and iopromide. Iran J Radiol. 2012; 9: 63-6. doi: 10.5812/ iranjradiol.7696.

35. Deng M, Chen SZ, Yuan J, Chan Q, Zhou J, Wang YX. Chemical exchange saturation transfer (CEST) MR technique for liver imaging at 3.0 Tesla: an evaluation of different offset number and an after-meal and over-nightfast comparison. Mol Imaging Biol. 2016; 18: 274-82. doi: 10.1007/s11307-015-0887-8.

36. Muller-Lutz A, Khalil N, Schmitt B, Jellus V, Pentang G, Oeltzschner G, Antoch G, Lanzman RS, Wittsack HJ. Pilot study of Iopamidol-based quantitative $\mathrm{pH}$ imaging on a clinical 3T MR scanner. MAGMA. 2014; 27: 477-85. doi: 10.1007/s10334-014-0433-8.

37. Gross C, Steiger K, Sayyed S, Heid I, Feuchtinger A, Walch A, Hess J, Unger K, Zitzelsberger H, Settles M, Schlitter AM, Dworniczak J, Altomonte J, et al. Model matters: differences in orthotopic rat hepatocellular carcinoma physiology determine therapy response to sorafenib. Clin Cancer Res. 2015; 21: 4440-50. doi: 10.1158/1078-0432. CCR-14-2018.

38. Muller WJ, Sinn E, Pattengale PK, Wallace R, Leder P. Single-step induction of mammary adenocarcinoma in transgenic mice bearing the activated c-neu oncogene. Cell. 1988; 54: 105-15.

39. Dai Z, Ji J, Xiao G, Yan G, Li S, Zhang G, Lin Y, Shen $\mathrm{Z}, \mathrm{Wu}$ R. Magnetization transfer prepared gradient echo MRI for CEST imaging. PLoS One. 2014; 9: e112219. doi: 10.1371/journal.pone.0112219.

40. Huang D, Li S, Dai Z, Shen Z, Yan G, Wu R. Novel gradient echo sequencebased amide proton transfer magnetic resonance imaging in hyperacute cerebral infarction. Mol Med Rep. 2015; 11: 3279-84. doi: 10.3892/mmr.2015.3165. 